\title{
APPLICATION OF BIM FOR STRUCTURAL ENGINEERING: A CASE STUDY USING REVIT AND CUSTOMARY STRUCTURAL ANALYSIS AND DESIGN SOFTWARE
}

\author{
SUBMITTED: February 2021 \\ REVISED: October 2021 \\ PUBLISHED: November 2021 \\ EDITOR: Bimal Kumar \\ DOI: $10.36680 /$ j.itcon.2021.053
}

\author{
Bedilu Habte, Associate Professor \\ School of Civil \& Environmental Engineering, Addis Ababa Institute of Technology \\ bedilu.habte@aait.edu.et \\ Eyosias Guyo \\ School of Civil \& Environmental Engineering, Addis Ababa Institute of Technology \\ eyosias24@gmail.com
}

\begin{abstract}
SUMMARY: Building information modelling (BIM) represents a workflow whose application on a construction project will enable all involved players to compile as well as work with information on every aspect of a building in a common model/database. Through BIM, the entire building can be virtually designed and built on a computer. BIM touches every part of a building's life cycle starting from the design phase well into the construction phase and beyond that into asset management. This research examines the experiences of early adopters of BIM and use that insight to introduce BIM, specially focusing on the structural analysis and design stage of a building. The study demonstrates how all structural design activities can be integrated with each other and how cross-discipline collaboration with the architect can be achieved through the adoption of BIM without leaving ones customary structural design platform. As a demonstration, a sample building is modelled using Revit along with conventional structural software packages ETABS and SAFE. Plugins and applications were developed for these software packages to facilitate interoperability amongst them so that they all act together as a single platform. Modelling, analysis, design and clash detections were facilitated by applying BIM. Major benefits of employing BIM in a structural design project are illustrated through this research.
\end{abstract}

KEYWORDS: BIM, Integration, Interoperability, Structural Analysis \& Design

REFERENCE: Bedilu Habte, Eyosias Guyo (2021). Application of BIM for structural engineering: a case study using Revit and customary structural analysis and design software. Journal of Information Technology in Construction (ITcon), Vol. 26, pg. 1009-1022, DOI: 10.36680/j.itcon.2021.053

COPYRIGHT: (C) 2021 The author(s). This is an open access article distributed under the terms of the Creative Commons Attribution 4.0 International (https://creativecommons.org/licenses/by/4.0/), which permits unrestricted use, distribution, and reproduction in any medium, provided the original work is properly cited. 


\section{INTRODUCTION}

During the life span of a building project, several professionals across various disciplines make their contribution, usually working in segregation. Each of them produces large amount of information and communicate, for the most part, through 2-D drawings. As a result, the design phase is plagued with fragmented works, data loss, unnecessary reworks, miscommunications, limited visualization and more. Thus, the design phase and the engineers involved in it can benefit from Building Information Modelling (BIM) - a technology that transforms the entire design process.

In BIM various professionals and players work cooperatively and share information efficiently to deliver a wellorganized design and construction process (François Denis, 2015). Through BIM, a virtual representation of a building containing both graphic and non-graphic information is created (Nielsen \& Madsen, 2010; S. Mehrbod, 2019). The final product of BIM will be a model that is data-rich, intelligent and parametric digital representation of a building or infrastructure (Sampaio, 2017).

With all these promises and advantages, the actual BIM implementation is, however, a huge undertaking. Interoperability among BIM software is still a challenge. There are difficulties in importing an IFC-Data (an industry standard format for BIM data exchange) from one BIM software to another (Chi Zhang et al, 2015). A single integrated software platform for all the phases of a building design and construction planning is yet to be achieved.

For a successful data integration and BIM implementation, the software packages used by structural engineers should be able to effectively exchange data with BIM packages. Most of such software packages come with some data exchange capability. However, not all of them comprise exchange of the vast amount of structural analysis and design data that is generated by structural analysis and design software. Thus, a data island is created where vast amount of important structural data is separated or left out from the common database.

This study tries to address the problem a structural engineer faces in reaping the benefits of BIM while still working within the usual analysis and design software. BIM is implemented on a $\mathrm{G}+12$ mixed-use building; architectural design is integrated with structural design through a common database; and structural object templates that are capable of storing structural analysis and design data are created. All the design activities are integrated through the development of tools and plugins programmed to mitigate the interoperability issues among the different software packages.

\section{LITERATURE REVIEW}

Building information modelling is a process in which the various stakeholders and professionals are working together and exchanging information to provide a more efficient design and construction process. Through a BIM process, a virtual prototype of the building can be developed (François Denis 2015). BIM covers the entire lifecycle of a building and it can create, coordinate, document, manage and update information about the building (Matarneh \& Hamed, 2017). The adoption of BIM on a building project results in a more integrated design and construction process and a better quality of building at lower cost and reduced project duration (Eastman, et al. 2011). Some of the benefits of BIM are early clash detection, improved collaboration and communication, improved visualization, improved time efficiency, well documented design process, improved quality of work, easier material quantities estimate (Berdeja, 2014; Bartley, 2017; Chen \& Tang, 2019; Sampaio, 2017; S. Mehrbodet al, 2019).

Unlike some of the misconceptions that arise from the naming, the BIM workflow is not only applicable for buildings; it can also be implemented in the design, construction and facility management of all forms of infrastructures (Bartley, 2017, Davies et al, 2017). Furthermore, it also goes beyond the preparation of a 3D model of a project by providing a wide range of applications throughout the life cycle of projects, such as combining the 3D model with parametric design, coordination, communication and visualization (Eastman, et al. 2011). These additional applications are referred to as "dimensions" that add functionality over the 3D model like (BIM Academy, 2017):

- $4 \mathrm{D}$ - to include the scheduling and project planning aspect,

- $5 \mathrm{D}$ - incorporates the cost estimation aspects,

- $6 \mathrm{D}$ - adds sustainability issues,

- 7D - considers the facility management aspect, etc. of the project. 
While CAD technology is limited to geometric data, parametric design is at the core of BIM models that allows to design or provide both the geometrical and non-geometrical data (Singh, Gu, \& Wang, 2011). For instance, the $\mathrm{CAD}$ representation depicts a wall as a rectangle with a reference point, while in a BIM representation it provides more intelligent information such as its usage, material, cost, fire-rating, etc. as a parametric model.

Eastman et al. (2011) studied and discussed the strength and weakness of the available BIM packages like: Revit, Bentley systems, ArchiCAD, Digital Project, Vectorworks, Tekla Structures, DProfiler and AutoCAD-based applications. Accordingly, Revit was found to be the best-known and the market leader for BIM implementation in architecture. A somewhat similar conclusion was reached by another study conducted by B.M. McGuire (McGuire 2016).

The challenges repeatedly mentioned by early adopters of BIM implementation are listed below (Sielker \& Allmendinger, 2018; Cheng J \& Lu Q, 2015; Chi Zhang et al, 2015):

- Lack of competent staff that possess BIM knowledge and skills

- $\quad$ Lack of BIM and cross-discipline education for engineering students

- Absence of information, resources, guidelines and standards on BIM implementation

- Absence of demand by clients due to lack of awareness

- Lack of government support and incentives

- $\quad$ Resistance to abandon the current work culture and adopt BIM workflow instead.

During a life time of a project, professionals from disciplines work cooperatively, traditionally based on the exchange of 2-D drawings and documents. However these professionals use 3D models during their individual work, yet still the collaboration remained more or less 2-D based (Singh, Gu, \& Wang, 2011). A common database provided by BIM improves collaboration and communication between structural engineers and the rest of the design team (Bartley, 2017). Any change made by the other design team members is automatically tracked by the structural engineer and vice versa. Accordingly, BIM makes it possible to merge all involved disciplines into a single central digital model (Berdeja, 2014).

Presently, multiple software packages with overlapping data requirements are used to perform various tasks during design and construction of a building. These packages need to exchange data amongst each other for BIM adoption. This ability to exchange data among software packages and for the packages to jointly contribute to the work at hand is called interoperability. IFC (industry foundation class) is a data format standard for the representation of building information for exchange among architectural, engineering and construction software packages. It offers a broad, general definitions of objects and data (Eastman, Teicholz, Sacks, \& Liston, 2011).

Nielsen \& Madsen (2010) carried out a study where they examined the interoparbility of Revit with structural analysis packages. These packages were Robot structure, StaadPro and an add-on for Revit structure. They analyzed five structures with varying complextity, with the aim to create a bidirectional link between Revit and the structural analysis and design packages. The first link, that is from Revit to the structural analysis and design packages, worked well while, the reverse link, that is from the structural analysis packages to Revit, was found to be very troublsome and at same cases impossible. The study discussed this unfortunate situation in detail but didn't went further to provide a solution. (Nielsen \& Madsen, 2010)

Xiao, Liu, Du, Yang, \& Xu promised to create a bidirectional mutual conversion between Revit and a structural analysis software named PKPM. However, on their paper, they only presented half of their intention. They were able to develop a model of a high-rise shear wall structure on Revit and transfer it to PKPM for structural analysis. However, they failed to present the other direction of the link that is sending the structural analysis model back to Revit. (Xiao, Liu, Du, Yang, \& Xu, 2019).

In this research, interoperability between Revit and conventional software packages (ETABS and SAFE) has been investigated. A bidirectional link between Revit and other structural software packages was achieved through the development of tools and plugins.

This research work is planned in light of the experiences and recommendations of the earlier BIM implementations, focusing on the structural design aspect. Specifically, interoperability between Revit and conventional software packages (ETABS and SAFE) has been investigated in this work. It attempts to provide a benchmark for future studies that should tackle the bidirectional link between the disparate software packages in BIM implementation. 
The following two chapters serve as the requirements analysis for the smooth interaction and integration between the structural software and the other software systems within the preferred BIM platform.

\section{MODEL PREPARATION}

\subsection{Platform Selection}

The application of BIM commences with the preparation of a central model. Ideally, the central model will serve as a common database for all the design data across multiple disciplines. For this research, Autodesk's Revit is selected as the BIM platform and the architectural model is prepared using Revit Architecture. Revit is, therefore, supposed to serve as the integration platform in this.

Revit Structure and Robot structural analysis software, both developed by Autodesk, are candidates for the purpose of analysis and design of a building. However, besides requiring a high learning curve, the authors found that these packages lack some capabilities for an exhaustive structural analysis and design. Many structural engineers are used to working on conventional structural software packages like ETABS and SAFE from CSI (Computers and Structures, Inc., 2018). Using such software packages that are already popular with the professionals will enhance the adoption of BIM. As a result, ETABS was selected for the superstructure, accompanied by SAFE for the substructure in this study.

\subsection{Creating the Analytic Model}

In a BIM workflow, when an architectural model is created, the corresponding structural model is also produced simultaneously, minimizing the modelling task of the structural engineer. The central model of the sample building investigated in this study is shown in FIG. 1. This model contains both architectural objects in (a) and structural objects, displayed in (b).
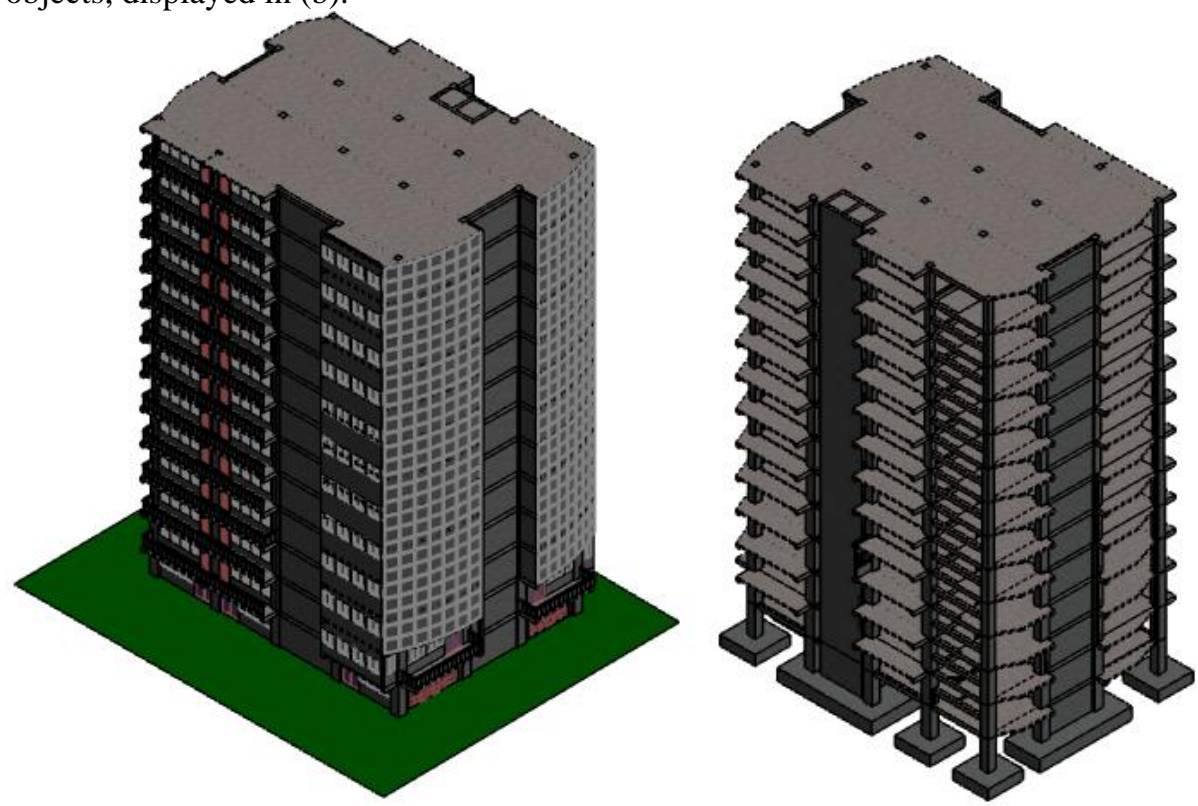

FIG. 1: (a) Central model of the complete project-Architectural Model (b) Structural Model

\subsection{Defining Project Information Parameters}

In Revit, "Project information" is a system family that possess default parameters to store information such as address, client name, etc. In the current version of Revit, there are no parameters that store project information required for structural analysis and design. Hence, such parameters capable of storing information required for structural analysis and design, classified as structural and geotechnical, are created in this research. 
A group of parameters that store information which is required for seismic design of the project including structural type, ductility class, seismic zone and bedrock acceleration ratio, spectrum type, ground type, behavior factor, importance class and factor, regularity in elevation and plan and fundamental period of vibration.

These are a group of parameters which store information gathered during geotechnical investigating of the site that are essential during the foundation analysis and design stage.

The structural and geotechnical parameters are created as "Shared parameters" - parameters that can be used in multiple projects. The project information parameters family created for this research is reusable in future BIM projects - this shows that reusability is an obvious advantage of adopting BIM.

\subsection{Defining Materials in BIM}

Important descriptions can be attached to the materials used in the building. Their preparation, any special care needed during preparation, cost and even manufactures can be suggested. Any other information that is relevant to the material can be attached to it.

Physical properties of anticipated materials in the structure that are required for the structural analysis and design task are specified as material properties in this work. These properties include thermal property, Young's Modulus, Poisson's ratio, shear modulus, density, compressive strength, yield strength, tensile strength, etc.

\subsection{Structural Objects in BIM}

Structural objects including beams, columns, slabs, shear walls and foundations are all part of the central model in Revit. By default, these objects are not able to store structural analysis and design information. Hence, such objects have been created and modified to make them capable of storing as many structural analysis and design information as possible. These act as template element (family in Revit terminology) that can be reused in different projects.

\subsubsection{Data organization and Revit object hierarchy}

Revit organizes objects in hierarchy in the central model. At the top of this hierarchy are categories followed by family, type and instance respectively. FIG. 2 illustrate this hierarchy using an example.

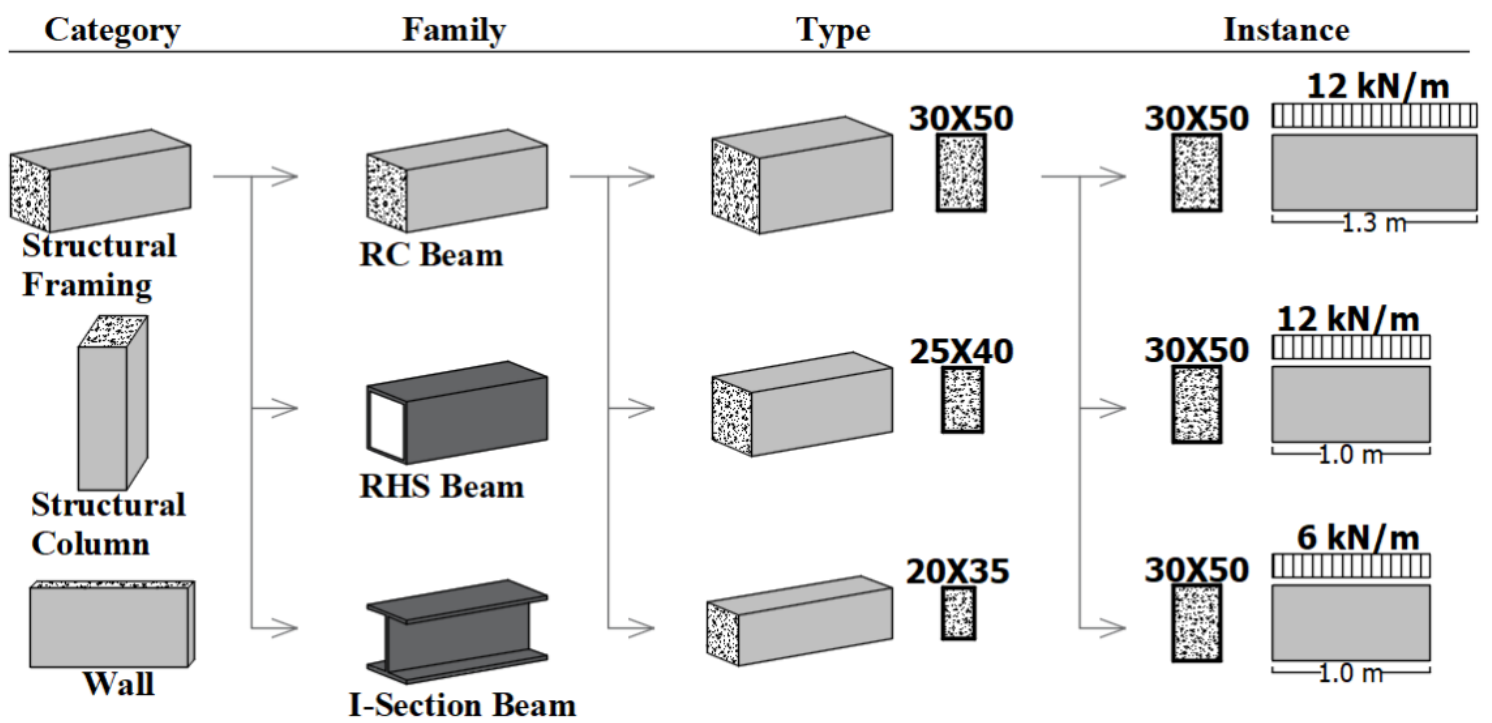

\section{FIG. 2: Revit object hierarchy illustration}

Categories are pre-defined parametric building components within Revit, that group together similarly functioning objects. They represent the different parts of the building such as walls, columns, beams, etc. FIG. 2 presents three model categories. Family is a collocation of like objects sharing some general behavior and properties. In FIG. 2, three Revit families are shown for structural framing category. Types are variations of a family; the RC beam family depicted in FIG. 2 has three types (distinguished by the different cross-sectional dimensions or properties). 
An instance is an actual physical object that is placed in the model. An RC beam (family) with cross section 30x50 has been instantiated three times as presented in FIG. 2 .

\subsubsection{Structural member families}

An $R C$ beam family, containing structural analysis and design parameters, is created in this research. Such a beam object can store information that encompasses different aspects of the beam essential for or resulting from the structural analysis and design.

Similar to the RC Beam family, an RC column family capable of holding sets of information that are relevant for the overall structural analysis and design activity, is also created in this work.

Unlike structural beams and structural columns, Revit does not allow the creation of structural wall family. Instead there is a wall system family. System families are built-in within Revit which cannot be created but can only be modified. This wall system family is incapable of storing structural analysis and design data. Therefore, parameters had to be created and added to the system family to expand its capability. Thus, analysis and design parameters were created and added to the wall system family, in this study.

Like structural walls, structural floors in Revit are also system families, capable of storing very limited amount of non-structural data, by default. To extend its storage capability to structural analysis and design data, a number of parameters were created and added to the floor system family as shared parameters.

Revit provides three foundation families. These are isolated footing family, wall footing family and foundation slab family. The foundation slab family is a system family and hence cannot be created. The other two, however, are non-system families and thus can be created and fully customized. All foundation objects in the model, including the isolated footings, were modeled using foundation slab system family.

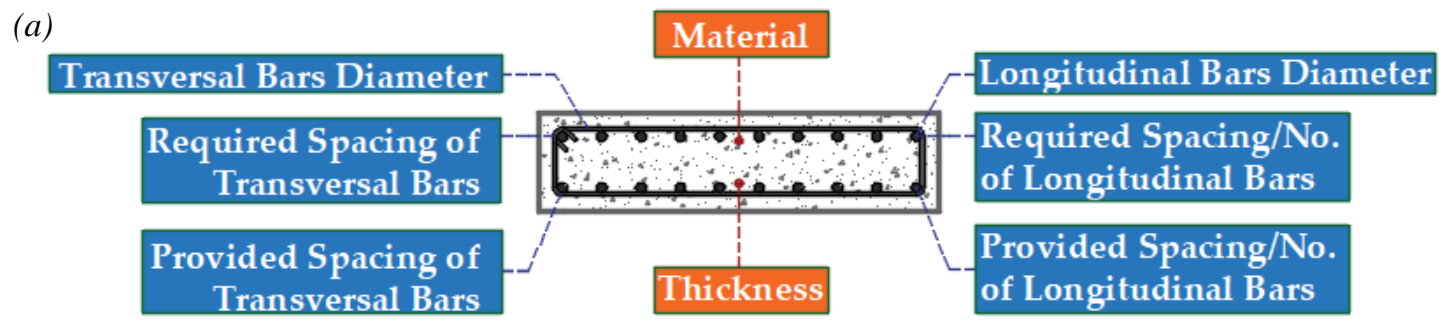

(b)

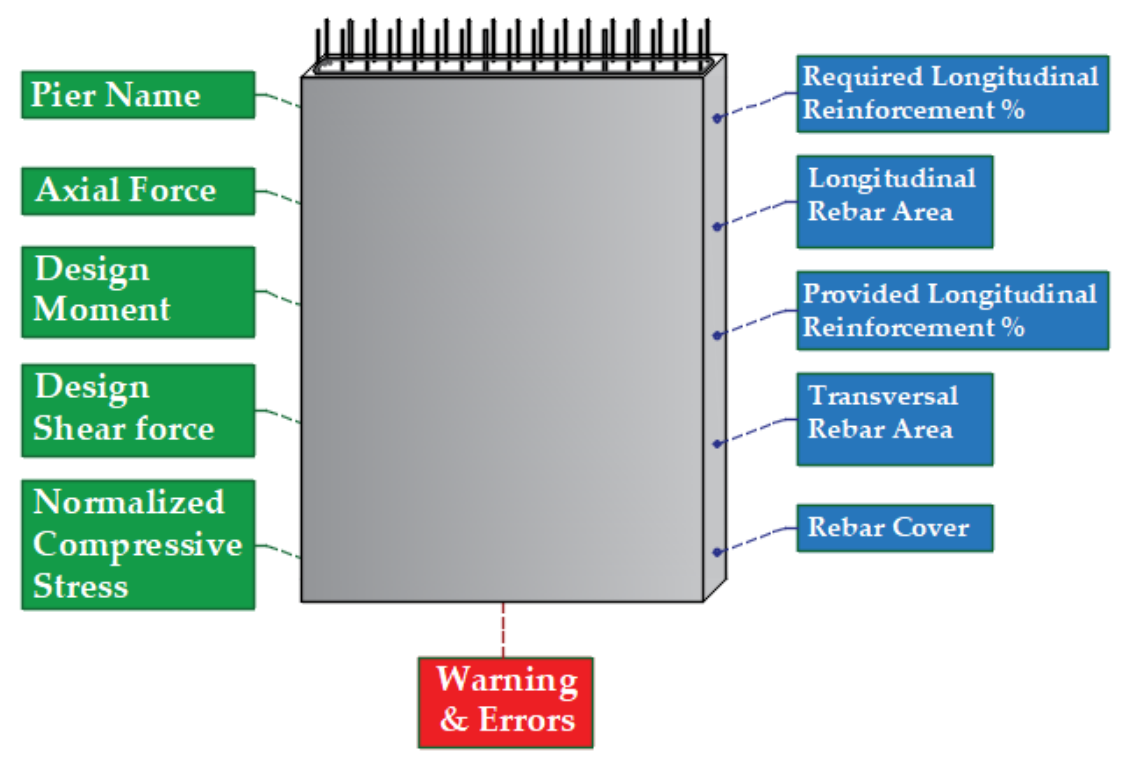

FIG. 3: Pier Wall parameters (a) Section view (b) Elevation view 


\subsection{Exporting Analytical Model for Structural Analysis}

For the data exchange of the analytical model between Revit, ETABS and SAFE, the CSiXRevit tool (developed by Computers and Structures Inc.) is used. It enables the exchange of information among Revit and the various CSI products (Computers and Structures, Inc., 2018).

However, the vast amount of data generated during structural analysis and design is completely ignored by the BIM package. This creates an information island where large amount of important structural data is entirely excluded from the central model. Through the tools and plugins developed in this study, structural related information generated by ETABS, SAFE and the tool themselves could be imported into the central model.

\section{ANALYSIS, DESIGN AND CLASH DETECTION}

\subsection{Introduction}

While the previous section dealt with the transfer of the analytic model to ETABS and SAFE for analysis and design, this section discusses the implementation of BIM within the actual structural analysis and design process, thereby developing the necessary tools and plugins.

\subsection{Analysis Results}

Load combination and load cases are best treated within the ETABS software. Usually, the structural engineer exports ETABS output parameters to a separate software to check analysis result against code requirements. The results of the verification remain on that separate file with no method to send them back to the model. Thus, plugins are developed to carry out the checks and verifications and retain the results for further use. Besides verification of code requirements, these tools further advance BIM implementation by providing a smoother work flow in the structural analysis phase.

\subsection{Foundation Analysis and Design}

From ETABS analysis, the reaction forces at the base of the structure were determined and migrated to SAFE. From the central model in Revit, the foundation objects with their preliminary dimensions were transferred to SAFE. After foundation design is carried out in SAFE, the foundation objects with their new dimensions and reinforcement details are sent back to Revit.

As part of this study, a tool has been developed to collect structural analysis and design results from SAFE and store these in the central model in Revit; further information on the development is provided in section 5.3.

\subsection{Design Results}

Design of structural objects by ETABS and SAFE is finalized by providing the required section sizes and reinforcement amounts in order to resist the design actions. This information requires further treatment for it to be implemented during building construction. Bar diameter needs to be specified and respective number of bars (or spacing of bars) has to be computed.

Tools and plugins were also developed as part of this research for handling design results of structural objects. These tools retrieve design data from ETABS and SAFE and prepare a rebar set. Furthermore, additional tools and plugins were developed to haul the structural data from ETABS and SAFE to Revit to be stored on the central model.

\subsection{Clash Detection}

During this research, the implementation of BIM workflow enabled an accurate and automated clash detection to be carried out. Unlike the conventional workflow, it comes with a built-in capability to detect collusions between objects. The summary of these collusions along with the number of times they occurred for the project considered in this research is given on Table 1. 
Table 1: Detected clashes between building objects

\begin{tabular}{|l|c|}
\hline Colluding objects & Number of occurrences \\
\hline Landing beam and windows & 13 \\
\hline Floor beams with windows & 3 \\
\hline Columns with doors & 16 \\
\hline Columns with hand rails & 12 \\
\hline Columns with lift shaft & 10 \\
\hline
\end{tabular}

\subsection{Preparing Construction Drawing}

The construction drawing for the sample project was prepared in Revit on the central model. The advantage of preparing construction drawing through BIM workflow over the conventional method were evident in both preparing the drawings and in reading them.

\section{TOOLS \& PLUGINS DEVELOPMENT}

\subsection{Bridging ETABS and Revit}

All the objects in Revit and ETABS have a unique id to identify them with. This id is automatically generated by the software platforms and can be changed by users. The unique id of a certain object in Revit (the central model) is identical with the id of that same object in ETABS. Whatever modifications the object went through; its unique id remains unchanged.

Another unique object identifier used both in ETABS and Revit is GUID. However, unlike unique id, GUID of objects change when they are moved from one platform to another (ETABS to Revit and vice versa). Consequently, GUID cannot be used to establish a bridge between the two software platforms. As a result unique ids are exclusively used as a link between ETABS and Revit as well as between SAFE and Revit in this study.

An SBIM file type (*. SBIM) was created as part of this research to be used as a means of communication between ETABS plugins and Revit plugin as well as SAFE plugin and Revit plugin. When an ETABS plugin saves or exports data, an SBIM file is created. Later, the Revit plugin will read this SBIM file, unload its content and load it onto the central model.

\subsection{Developing ETABS Tools for BIM Implementation}

The tools and plugins are developed using C\# programming language in Microsoft visual studio 2015. The entire development process including debugging and testing took one year to complete. The details of the tools and plugins developed in this work are described in the following sections.

\subsubsection{ETABS Tool}

The internal process of the programmed ETABS tools has some similarities. FIG 4 presents the general flowchart of the tools. The first block of codes attempts to get access to ETABS's API. Then, the tools will verify whether the required ETABS data is available. Most of the data generated and made available by ETABS is provided as a set which requires an organization. That is followed by performing the actual function of the particular tool, which is unique for each particular tool.

Finally, The ETABS tools present the result from their computation in tables. Some of the tools provide result for observation. Based on the observation, changes may be made to the ETABS model. Other tools, provide the opportunities for modification of the result itself. At the end, all the data that was generated by ETABS and later organized and processed by the particular tool is exported into an SBIM file and imported back into the central model in Revit. 


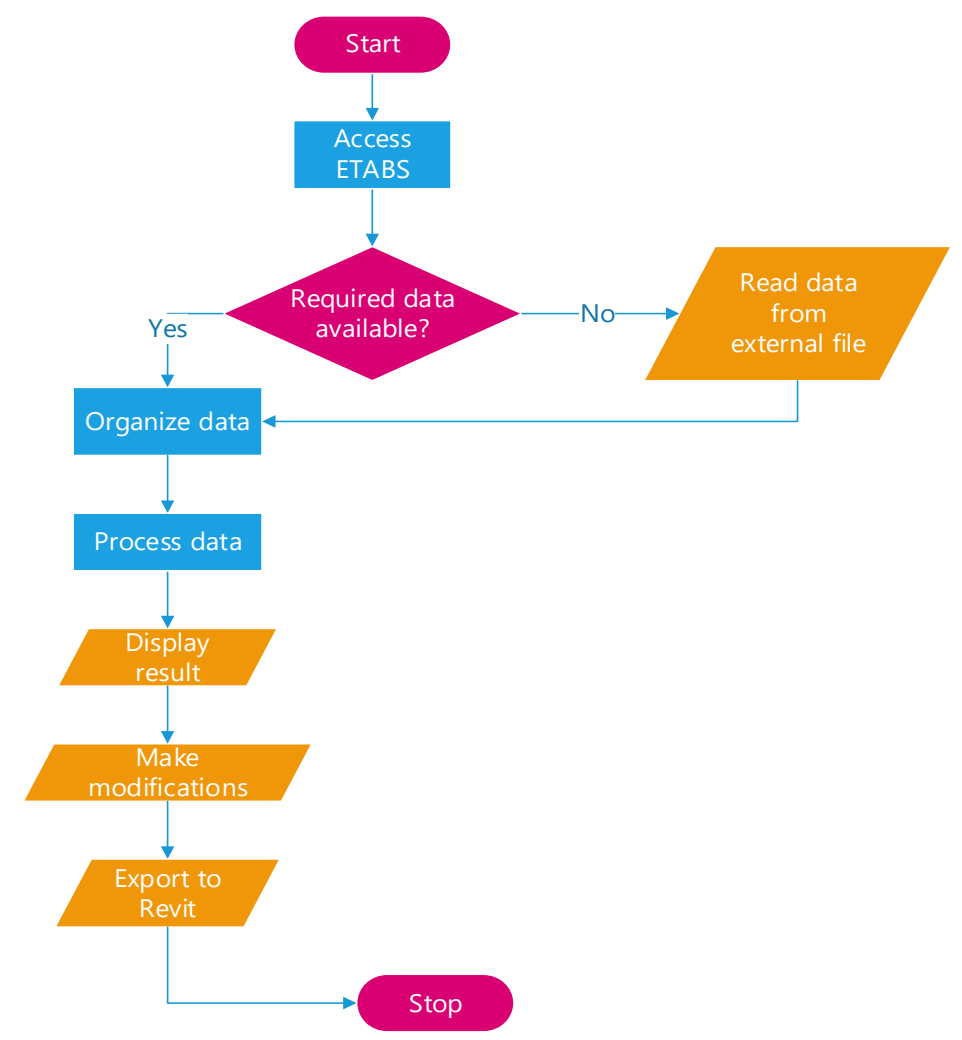

FIG. 4: ETABS tool's general flowchart

\subsubsection{Story Data Manager Tool}

This tool carries out five tasks. It extracts the structural analysis data generated for the stories by ETABS, computes inter-story drift sensitivity coefficients and damage limitation parameters for each story and verifies whether the requirements for regularity in plan and elevation has been mate according to European building design code.

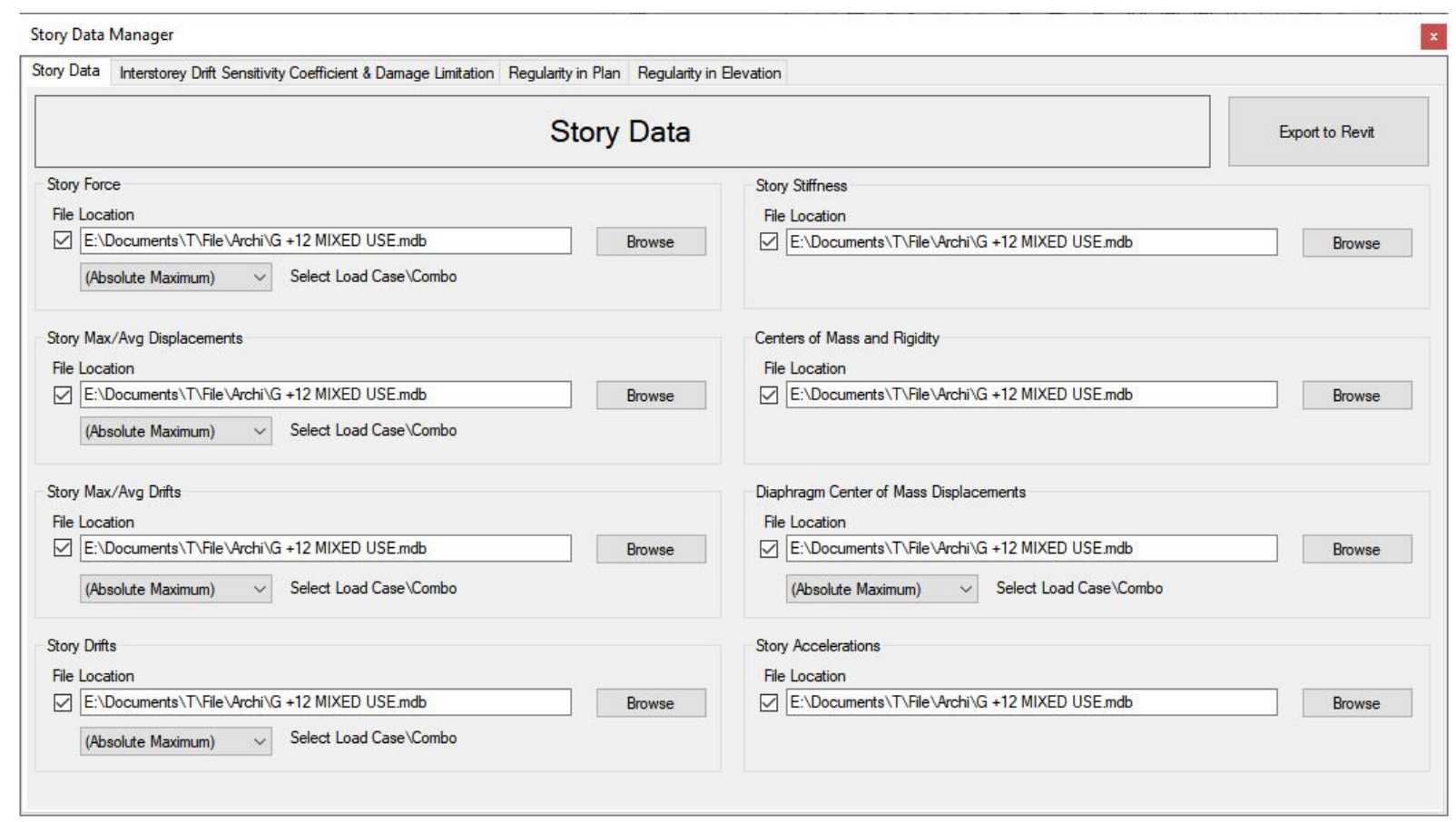

FIG. 5: Story Data Manager Tool GUI 


\subsubsection{Wall Analysis and Design Manager Tool}

This tool was developed to extract analysis and design data for all structural walls, determine a rebar set and export the result. Later, this result will be read by a Revit plugin that will store the data on the central model. The tool will handle, pier and spandrel type walls.

\subsubsection{Beam Design Manager Tool}

This tool will filter out the beam from the rest of the frame objects in a given model. Then it determines a rebar set which includes both longitudinal and transversal bars by using the users input as a preference. The user can further manipulate the rebar set manually if necessary. As usual the final results are exported to later be imported by the tool developed for Revit and stored in the central model.

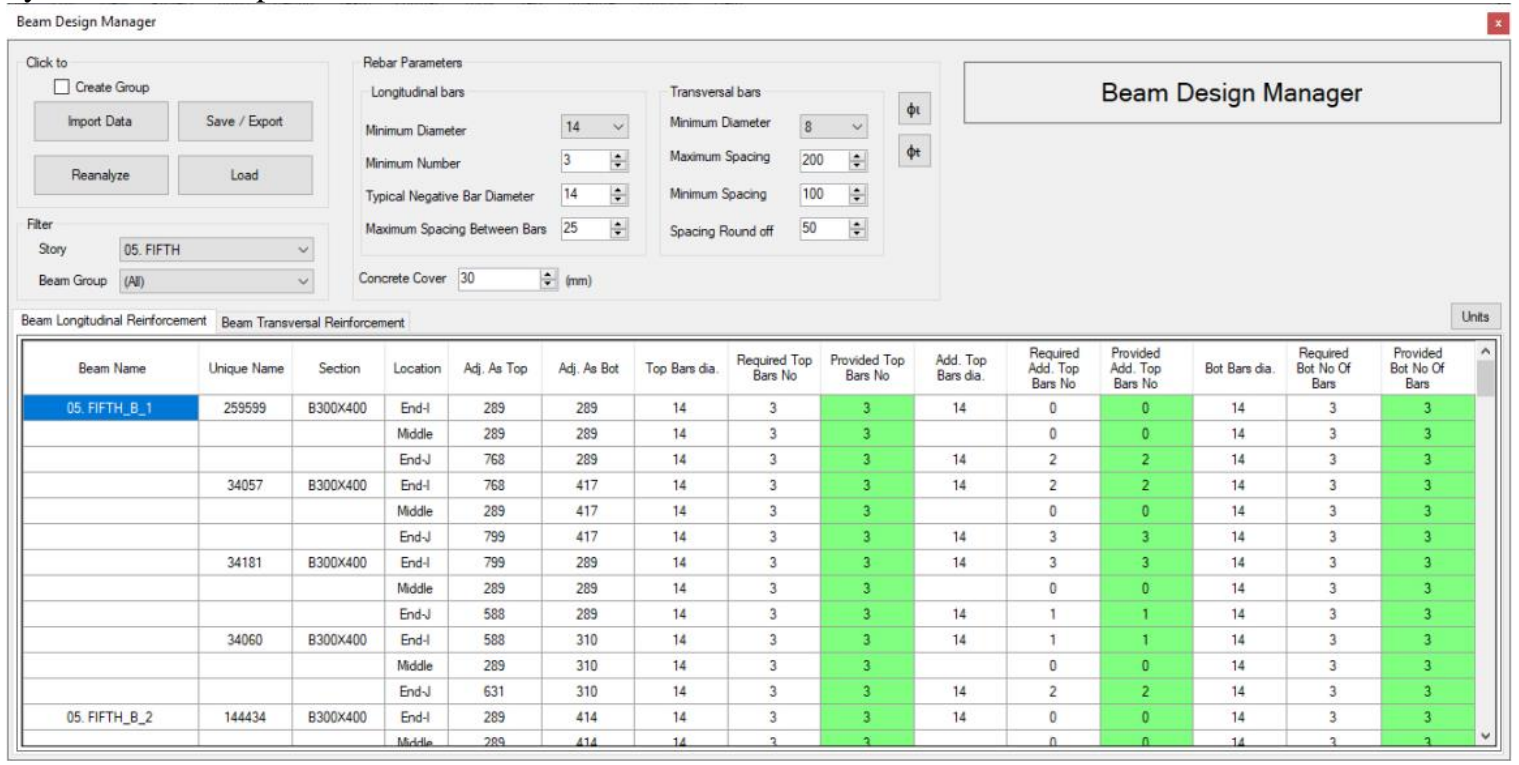

FIG. 6: Beam Design Manager Tool GUI

\subsubsection{Column Design Manager Tool}

This tool performs the same tasks as the Beam Design Manager tool except that it is for column. The tool will assemble columns from bottom floor to top and determine longitudinal as well as transversal rebar ser. Data exporting is also included same with the other tools.

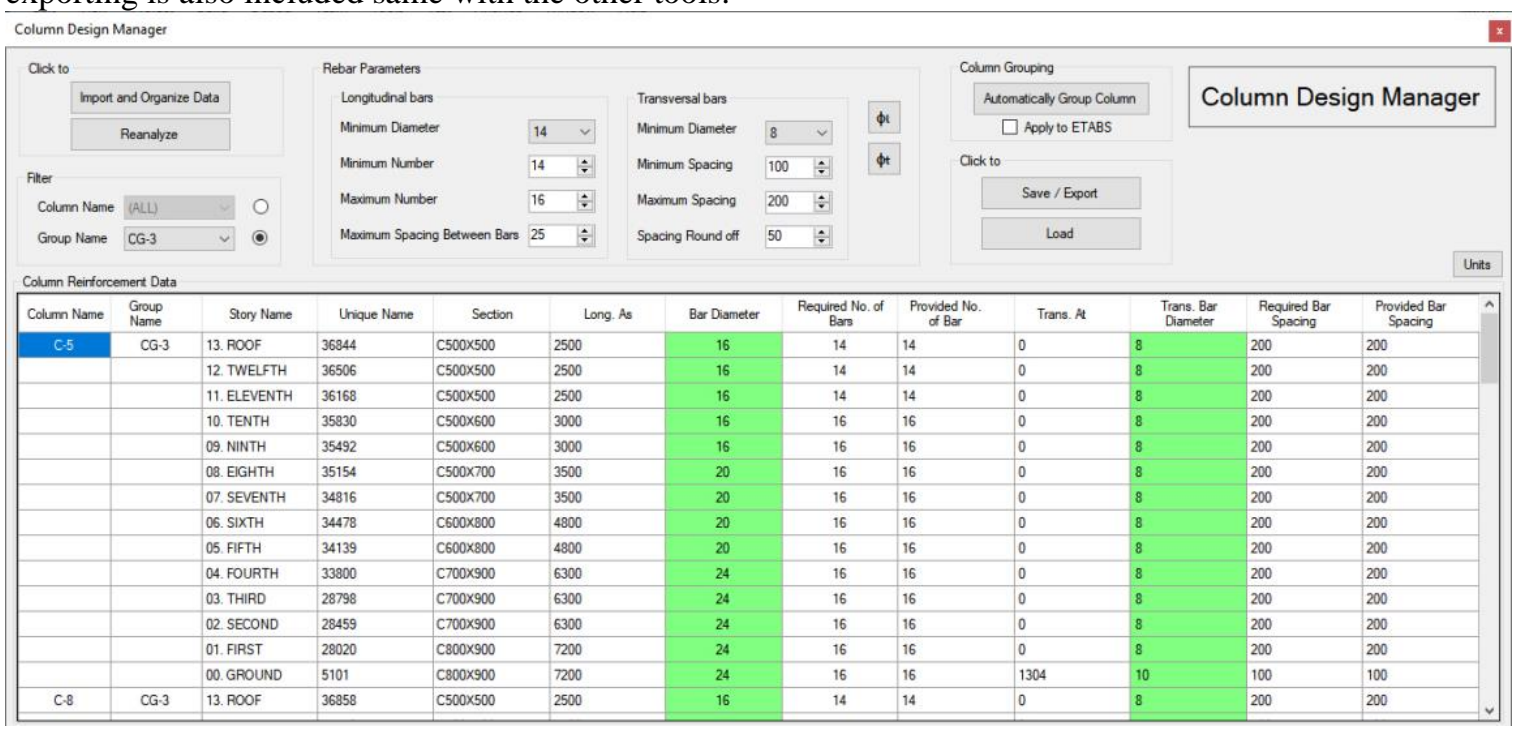

FIG. 7: Column Design Manager Tool GUI 


\subsubsection{Slab Analysis and Design Manager Tool}

This tool will pull all the area objects defined in ETABS. Among these area object, the tool will filter out the floor area objects (structural slabs). Then, the story level and thickness and the analysis results of each floor area is retrieved.

ETABS has two design bases for slab design: finite element based and strip based. The result of finite elementbased design is not available through output tables. The strip-based design provides output tables and it can also be directly accessed from ETABS. However, the outputs do not link a design strip with the slab being design. Thus, the design results for slabs cannot be retrieved automatically. Consequently, the designer is expected to manually provide design results to the tool.

\subsubsection{Frame Design Forces Manager Tool}

This tool will handle the design forces determined for frame objects, specifically beams and columns, by ETABS. These forces include axial forces, shear forces, bending moments and torsional moment. The design forces for slabs, walls and footings are extracted by the tools that were developed to manage the design of those elements. Afterwards, the tool exports the design forces of all frame objects along with their unique id to Revit through SBIM file.

\subsection{SAFE Tools Development}

Unlike Revit and ETABS, SAFE 2016 does not come with an API (application programing interface) that give access to its core. Neither a plugin nor an external tool can be programmed to extract information directly from SAFE. Thus, for this research, an indirect way was used to extract important data from SAFE. Like ETABS, SAFE allows outputs to be exported in MS Access files. A tool was created to read and extract important data from these output files.

\subsubsection{Foundation Analysis and Design Manager Tool}

The flowchart of this tool can be seen on FIG 8. It begins by locating the SAFE output files. Then, the data is organized and displayed. Finally, the data extracted from SAFE is exported in SBIM file format.

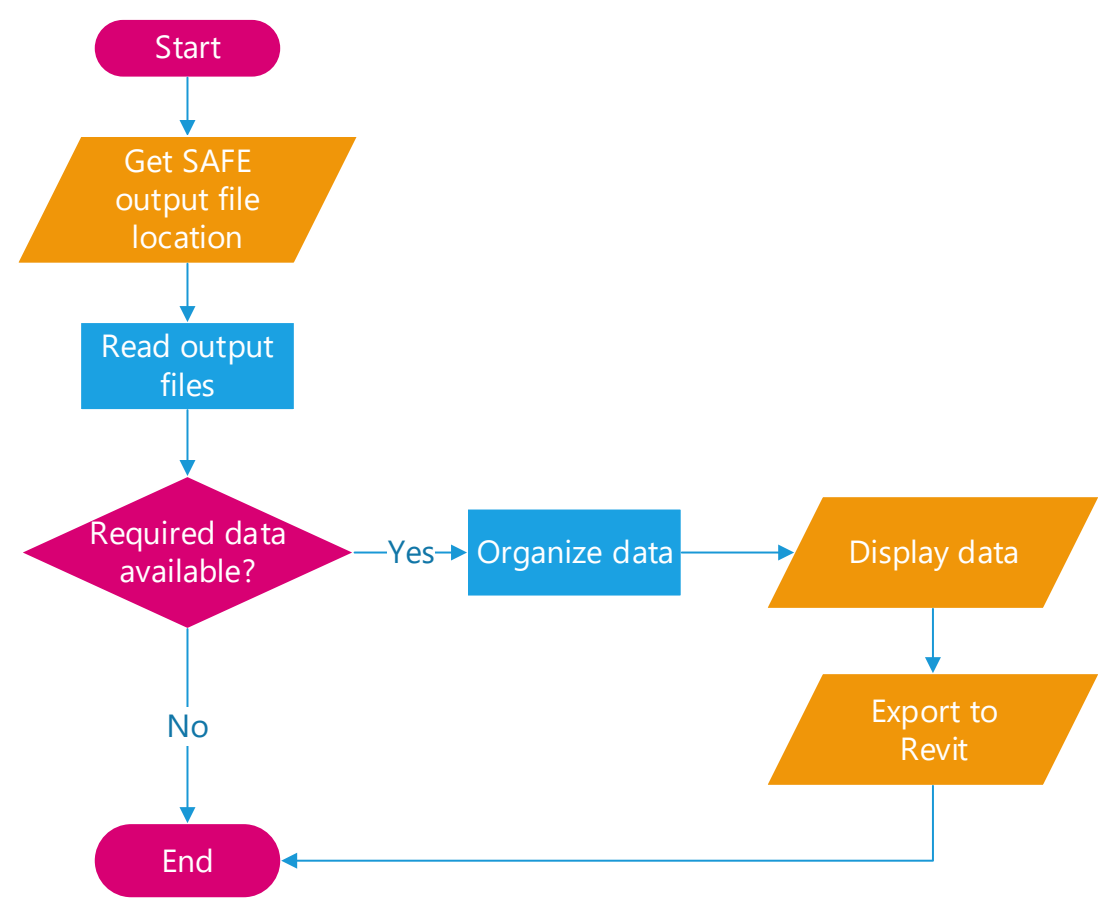

FIG. 8: Foundation analysis and design manager tool flowchart 


\subsection{Revit Plugin Development}

Developing plugin for Revit is harder and more laborious than doing the same for ETABS. This stems from the fact that Revit's API cannot be accessed by external application. Only in-process plugins are run in Revit. This leads to a more strenuous programming experience as compared to ETABS. As a result, coding of Revit plugin is kept to the minimum necessary. Most part of the interoperability is handled by the tools on the ETABS side.

\subsubsection{Import Data Plugin}

A single Revit plugin, titled "Import Data", was program to perform all the required tasks in Revit end of the data exchange. This plugin is able to communicate with all the ETABS plugins and tools as well as the SAFE tool.

Its task begins by locating and reading structural BIM (*. SBIM) files containing story data, wall analysis and design data, beam design data, column design data, slab analysis design data, foundation analysis and design data and frame design forces data. These SBIM files are the once created by the ETABS plugins and the SAFE tool. The Revit plugin will load the content of these output files. The data on these files is well organized so no organization is required here.

All available data of a structural object is grouped with its unique id. Hence, each object is called by the Revit plugin one by one using its unique id and receives all associated data. As such, interoperability is achieved.

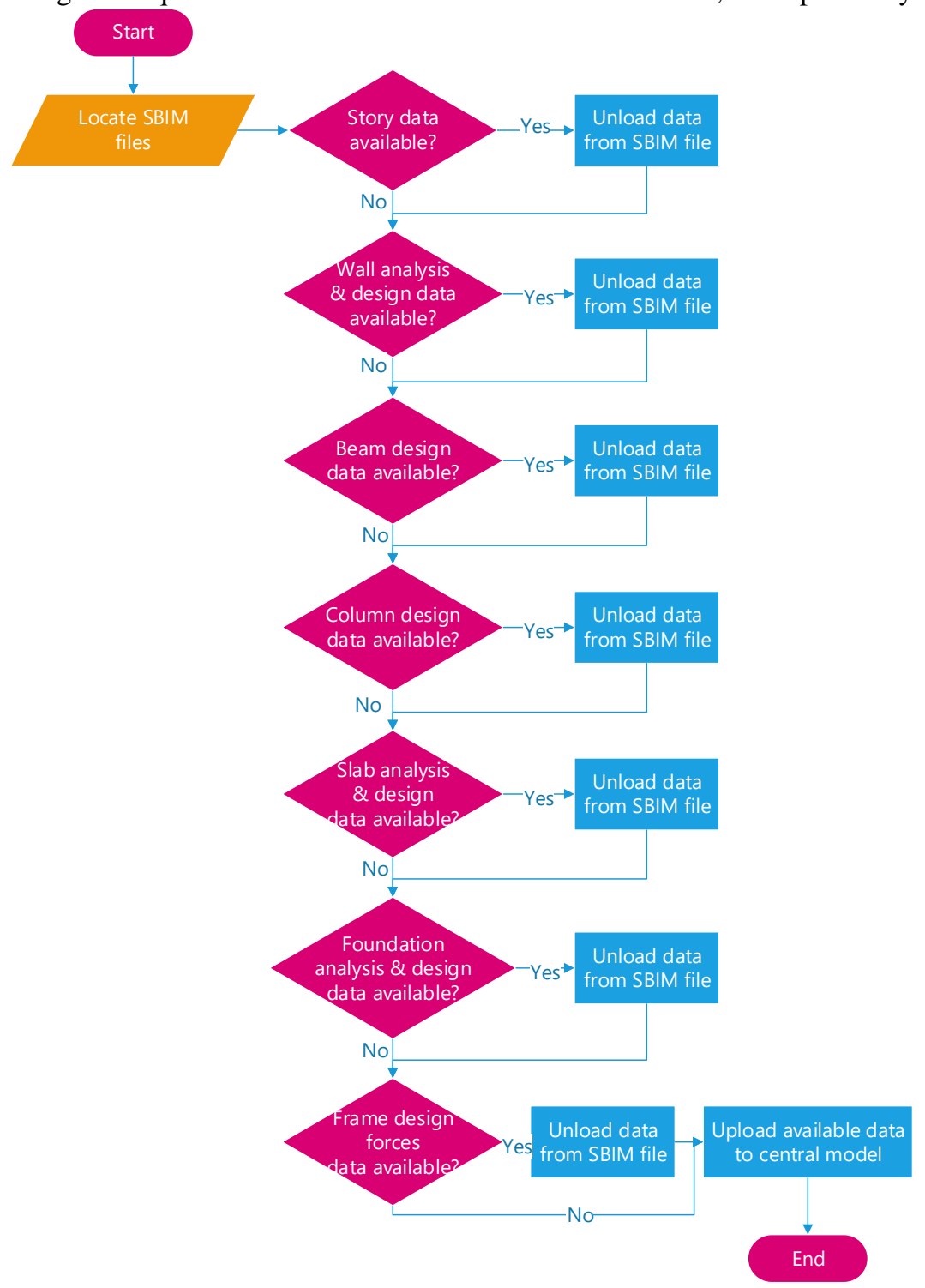

FIG. 9: Flowchart for the Import Data Plugin 


\section{CONCLUSIONS}

During the research, a BIM workflow was implemented on the structural design phase of a sample building project. BIM was involved in every phase of the structural design. Preparing the structural model, analysis, design, verifications, preparation of construction detailing and clash detecting were all aided by BIM.

Drawing out the structural model from the architectural model proved to be more advantageous than creating it anew. The structural model was created far more quickly and it perfectly captured the essences and complexity of the architectural model. Same is true for preparation of construction detail drawings.

Existing structural object in Revit do not have the capacity to store structural analysis and design results. Hence, objects that are capable of storing such information were created. This information was created on structural analysis packages ETABS and SAFE. The interoperability of these packages with Revit was expanded to include the migration of structural analysis and design results by developing tools and plugins.

Furthermore, the tools and plugins developed served to integrate fragmented structural design tasks. Computations that are not performed by ETABS are introduced to ETABS through the plugins. The result of those plugins, similar with the result of ETABS analysis and design, is stored in the central model. At the end, the central model was rich with structural data.

The structural object families and the various structural analysis \& design parameters created during this research can be reused in future building project, with or without modification, to implement BIM workflow. Likewise, the tools and plugins developed during this research can be reused in other building project.

While the BIM workflow presented in this research was geared towards structural engineering, the techniques followed can be adopted for the integration of other disciplines such as sanitary engineering and electrical engineering.

\section{REFERENCES}

BIM Academy (2017). First Steps to BIM Competence: A Guide For Specialist Contractors. London, United Kingdom, United Kingdom: Building Engineering Services Association (BESA).

Cheng J, Lu Q (2015). A review of the efforts and roles of the public sector for BIM adoption worldwide, ITcon Vol. 20, pg. 442-478, http://www.itcon.org

Chi Zhang, Jakob Beetz, Matthias Weisen (2015). Interoperable validation for IFC building models using open standards, ITcon Vol. 20, pg. 24-39, http://www.itcon.org.

Computers and Structures, Inc. (2018). CSiXRevit Version 2019.0. Release Notes. USA.

Davies K, Wilkinson S, McMeel D (2017) A review of specialist role definitions in BIM guides and standards, ITcon Vol. 22, pg. 185-203, http://www.itcon.org

Eastman, C., Teicholz, P., Sacks, R., \& Liston, K. (2011). BIM Handbook: A Guide to Building Information Modeling for Owners, Managers, Designers, Engineers, and Contractors (2 ed.). Hoboken, New Jersey, United States of America: John Wiley \& Sons, Inc.

ETABS, The ultimate integrated software package for the structural analysis and design of buildings, CSI Inc., Available online at: https://www.csiamerica.com/products/etabs, last visited on 15 Feb., 2021.

François Denis, (2015). Building Information Modeling - Belgian Guide for the construction Industry. Brussel: ADEB-VBA.

Nielsen, A. K., \& Madsen, S. (2010). Structural modeling and analysis using BIM tools. Aalborg: Aalborg University.

REVIT, Multidisciplinary BIM software for higher-quality, coordinated designs, Autodesk Inc., Available Online at: https://www.autodesk.com/products/revit/, last visited on 15 Feb., 2021.

SAFE, The ultimate tool for designing concrete floor and foundation systems, CSI Inc., Available online at: https://www.csiamerica.com/products/safe, last visited on 15 Feb., 2021. 
Sampaio, A. Z. (2017). BIM as a Computer-Aided Design Methodology in Civil Engineering. Journal of Software Engineering and Applications, 10, 194 - 210.

Sielker, F., \& Allmendinger, P. (2018). International experiences: Future Cities and BIM. Department of Land Economy. Cambridge: University of Cambridge.

S. Mehrbod, S. Staub-French, N. Mahyar, M. Tory (2019). Beyond the clash: investigating BIM-based building design coordination issue representation and resolution. Journal of Information Technology in Construction (ITcon), Vol. 24, pg. 33-57, http://www.itcon.org/ 